\title{
Zellweger Spectrum Disorder
}

National Cancer Institute

\section{Source}

National Cancer Institute. Zellweger Spectrum Disorder. NCI Thesaurus. Code C146639.

A group of conditions with overlapping signs and symptoms. It includes Zellweger

syndrome, neonatal adrenoleukodystrophy, and infantile Refsum disease. 